\title{
Self-efficacy, subjective well-being and positive coping in adolescents with regard to Covid-19 lockdown
}

\author{
Elena Cattelino ${ }^{1}$ (D) $\cdot$ Silvia Testa ${ }^{1}$ (D) $\cdot$ Emanuela Calandri $^{2}$ (D) $\cdot$ Angela Fedi $^{2}$ (D) $\cdot$ Silvia Gattino $^{2}$ (D) $\cdot$ Federica Graziano $^{2} \cdot$ \\ Chiara Rollero $^{2}$ (D) Tatiana Begotti $^{2}$ (D)
}

Accepted: 1 June 2021

(C) The Author(s), under exclusive licence to Springer Science+Business Media, LLC, part of Springer Nature 2021

\begin{abstract}
The study is aimed at examining the relationship between emotional and self-regulated learning self-efficacy, subjective wellbeing (SWB) and positive coping among adolescents and youths, during the COVID-19 pandemic lockdown. 485 Italian students (74\% girls; mean age 19.3) filled in an online questionnaire during the lockdown period. The hypothesized model in which both the forms of self-efficacy were predictors of SWB and positive coping, and SWB partially mediated the relation between self-efficacy measures and positive coping was tested by means of Structural equation modeling. Results largely supported the hypothesized relationships and suggested paying special attention to adolescents' self-efficacy in regulating basic negative emotions, in order to promote positive coping strategies to face challenges coming from everyday life and from nonnormative events.
\end{abstract}

Keywords Subjective well-being · Affective self-efficacy · Self-regulated learning self-efficacy $\cdot$ Positive coping $\cdot$ Adolescence COVID-19

\section{Introduction}

From March 9th to June 3rd 2020, Italy was subjected to complete lockdown as a result of the spread of the coronavirus disease 2019 (COVID-19). In response to controlling the outbreak, different emergency measures have been introduced such as the compulsory use of face masks, physical distancing, home confinement, closure of schools, universities and other educational institutions.

The lockdown resulted in a sudden and unpredictable loss of many of those activities that are particularly important for

All of the authors have agreed to the by-line order and to the submission of the manuscript in this form.

\author{
Elena Cattelino \\ e.cattelino@univda.it \\ Silvia Testa \\ s.testa@univda.it \\ Emanuela Calandri \\ emanuela.calandri@unito.it \\ Angela Fedi \\ angela.fedi@unito.it \\ Silvia Gattino \\ silvia.gattino@unito.it
}

daily life and for the development of adolescents and young people such as the interruption of school and leisure activities, social isolation, lack of autonomy, often accompanied by a dramatic change in parents' work activities (working from home, wage reduction, job loss) and no less by the loss of loved ones and those suffering long-term. All this has been a source of stress and emotional and psychological distress in children (Morelli et al., 2020; Morelli et al., 2021), adolescents and young people. The World Health Organization has highlighted how the pandemic can have negative consequences on psychological well-being (WHO, 2020) and, even
Federica Graziano federicagra@tiscali.it

Chiara Rollero

chiara.rollero@unito.it

Tatiana Begotti

tatiana.begotti@unito.it

Department of Human and Social Sciences, University of Valle d'Aosta, strada Cappuccini 2a - 11100, Aosta, Italy

2 Department of Psychology, University of Torino, via Verdi 10 10124, Torino, Italy 
if official statistics on significant samples are still relatively scarce, the first published data show an increase in feelings of malaise, varying from loneliness, worry, helplessness and fear, to depressive and anxiety symptoms (Duan et al., 2020; Loades et al., 2020; Saurabh \& Ranjan, 2020). It is particularly true for adolescents and young people (Pierce et al., 2020) who have had to face a prolonged lockdown with a confinement at home in a period of their development which is normally characterized by a strong need for autonomy, the desire for experimentation, a progressive independence from parental figures and a redefinition of relationships with peers (Jackson \& Goossens, 2006; Arnett, 2011). It is important to highlight that in Italy the majority of young university students still live at home with their families (Bonino \& Cattelino, 2012). Furthermore, the social and economic consequences of the pandemic have created a situation of greater uncertainty for the future which has repercussions especially on young people who are attempting to make important choices about their future.

Nonetheless, numerous adolescents and youths were relatively serene during the lockdown, and experienced feelings of subjective well-being and managed to use positive coping strategies. It is therefore useful to understand which factors are related to these feelings of well-being in the light of the current global health emergency and in the case of any future pandemics or periods of lockdown.

\section{Subjective Well-Being}

The subjective well-being (SWB) is defined by Diener and colleagues as a person's cognitive and affective positive evaluation of his or her life (Diener et al., 2002). From this perspective, well-being is considered subjective as it derives from an individual evaluation of one's sense of wellness and it is characterized by two components: the cognitive, that usually corresponds to the life satisfaction, and the affective, that corresponds to the predominance of positive affect over negative affect (Deci \& Ryan, 2008).

Recently, Caprara and colleagues have suggested that the cognitive component of SWB should be extended by the positivity (POS) that adds self-esteem and optimism to life satisfaction (Caprara et al., 2017). While life satisfaction refers to an evaluation of different life domains, self-esteem concerns the overall evaluation of oneself as a person, and optimism refers to a general evaluative judgment about the future, concerning the expectation that many positive and few negative things will happen. Self-esteem, life satisfaction and optimism share common evaluative processes which turn into a general positive outlook towards oneself, life and future (Caprara \& Steca, 2005).

The affective component of SWB is instead considered in terms of hedonic balance, the difference between positive and negative affects experienced in various life situations, and it is often called happiness. Both affective and cognitive components of SWB have been analysed in many studies in the last two decades and a great deal of attention has been paid, on the one hand, to the effects of SWB in the individual's life and, on the other hand, to the factors that can influence SWB in varying conditions of individuals' lives and in diverse phases in the life span. Recent studies have focused their interest on the functional and dynamic role of SWB that was conceptualized as a system which both responds to and promotes success in various life domains and fosters positive functioning over time (Busseri \& Sadava, 2013; Diener, 2008). As far as effects are concerned, both affective and cognitive components appear to impact many positive healthy outcomes, coping (Jiang et al., 2019) and resiliency (Fredrickson \& Joiner, 2018).

According to Shmotkin's perspective (2005), SWB can play an adaptive role in facing adverse situations: high levels of SWB allow individuals to maintain the focus on tasks without being disrupted, thus promoting the motivation to approach the problem instead of avoiding it. As stressed by Dahl (2001) achieving SWB is of even greater importance when adolescents experience a stressful life event, due to its critical role in coping with the demands of the stressful situation and thus becoming resilient with respect to the negative event.

As far as the factors influencing SWB, a great body of research has highlighted the role of predictors and correlates concerning individual, contextual and cultural factors. Amongst these, the self-efficacy beliefs were found to exert an important role on positive thinking (cognitive component) and hedonic balance (affective component of SWB; Bandura, 1997; Caprara \& Steca, 2005). Life experiences have an impact on SWB and, in particular, prolonged lockdowns and worries related to the pandemic can negatively affect both positivity and hedonic balance. Drastic restrictions and sudden changes in lifestyles and daily routines, particularly among young people, can negatively affect their life satisfaction; the limitations and additional difficulties in coping with the developmental tasks typical of adolescence and youth can affect self-esteem; no less important is the negative effect created by the very real uncertainty regarding the economic and social crisis relating to optimism and future plans.

\section{Coping Strategies}

Coping refers to how people try to manage traumatic events or everyday stressful situations; it is considered a process that arises in situations that strongly test the resources of an individual. Coping plays a pivotal role in adolescence that is a particular period during which individuals deal with new challenges that can represent, at the same time, opportunities for growth or sources of uncertainty and stress; such challenges are oriented to important developmental tasks, such as identity construction, autonomy acquisition, and life goals, all 
components of psychological well-being (MayordomoRodríguez et al., 2015).

In recent years, various publications have questioned which coping strategies are best associated with distress reduction and wellbeing; actually, it is known that different coping strategies may be equally effective and that they may differ on the base of the kind of stressors (Shiota, 2006). Since the ways of coping and managing stressful situations are diverse, numerous studies have proposed different coping strategies and attempted to categorize them. One of the first types of categorization was published by Folkman and Lazarus (1985) and it distinguished between two primary coping styles: problem-focused which consists of dealing with stress and emotion-focused, directed at handling one's emotional response to stressors. Other findings, as reported in Litman's review (Litman, 2006), suggest it may be more meaningful to distinguish between a positive, approachoriented style which includes socially-supported and selfsufficient coping strategies, and a negative, avoidance oriented form of coping. Recently, Sica et al. (2008) have divided classification into five broad dimensions: avoidance strategies, social support, positive attitude, problem orientation and transcendent orientation. Avoidance strategies refer to the use of heterogeneous strategies ranging from denial, substance abuse, to mental and behavioral detachment; social support refers to the search for comfort, information and emotional release; positive attitude highlights acceptance, containment and positive reinterpretation of events; problem orientation refers to the use of active and planning strategies; finally, transcendent orientation refers to religion and the absence of humour.

In line with previous studies (see Litman, 2006), positive attitude and problem orientation are considered strategies associated with greater well-being. The present study examines and analyses these two strategies as positive coping methods linked to a greater feeling of control over events and the search for useful information to deal with difficulties. As stressed by Zambianchi and Bitti (2014) proactive coping represents one of the most significant abilities that can help the younger generations to improve their level of overall functioning.

There is a clear reciprocal relationship between SWB and coping strategies. In many previous studies, coping strategies are regarded as predictors of diverse outcomes such as risk behaviors (deviant behavior and substances abuse) and depressive feelings; whereas only few studies have examined the possible role of psychological well-being as a personal resource that could favour adaptive coping in adolescence (Zajacova et al., 2005; Freire et al., 2016): higher levels of psychological well-being lead to the adoption of adaptive coping strategies. In this peace of research, coping strategies are analysed as an outcome due to the assumption that, during the current pandemic and successive prolonged lockdowns that are historically unique, those with higher SWB levels are more equipped at dealing with the lockdown experience with positive coping strategies.

\section{Emotional and Self-Regulated Learning Self-Efficacy Beliefs}

Perceived self-efficacy consists in the personal belief of being able to face new situations, difficulties and challenges (Bandura, 1997). This is an important self-regulation mechanism that plays a central role in the self-management processes because it affects actions directly and through its impact on cognitive, motivational, affective and decisional determinants (Bandura, 1997; Bandura et al., 2003). Adolescents and young adults increase their agency, and their self-efficacy beliefs become central to the choices and management of circumstances and empower them to cope with the demands of everyday life (Lerner \& Steinberg, 2009; D'Amico et al., 2013; Cattelino et al., 2019). Thus, self-efficacy could be a significant individual resource that can promote adolescent functioning and well-being (Yap \& Baharudin, 2016).

Previous studies have shown that the self-efficacy beliefs, even with respect to specific areas and tasks, work together, in synergy. As adolescents face complex challenges, multiple self-efficacy beliefs do not operate in isolation from one another, but together contribute to positive and negative psychosocial outcomes (Bandura, 1997; Caprara et al., 2006).

The present study examines the synergy of affective and self-regulatory learning self-efficacy and their relationships with subjective well-being. This choice derives from the fact that, during the dramatic first wave of COVID-19 and the successive lockdown, adolescents and young people had to face two particularly demanding challenges: the first was that of managing the whole range of their emotions and the second, regulating their learning processes by studying and attending lessons online.

Although other types of self-efficacy may equally be affected by the pandemic (for example, career development selfefficacy), in the present study those most relevant to the immediate current situation and most significant for adolescents and youths in the Italian context were selected. A recent study conducted in Italy during the pandemic lockdown reported that online learning was not a completely satisfactory substitute for traditional schooling and a large proportion of adolescent students expressed genuine worries about their academic progress (Pigaiani et al., 2020).

Emotional self-efficacy reflects a person's perceived abilities to manage negative emotions (anger, sadness and fear) and to express positive ones (joy, enthusiasm and pride); it plays a pivotal role in the management of different stressors and in influencing depression (Bandura et al., 2003; Calandri et al., 2021) and well-being (Caprara \& Steca, 2005). Numerous studies of Caprara et al. (2006, 2008, 2017) have highlighted that people's perceived capability in regulating 
their positive and negative emotions positively influenced both cognitive and affective SWB.

Self-regulated learning self-efficacy refers to the person's perceived abilities to manage difficulties associated with studying and with active participation in school or academic activities. Students with good self-regulated learning selfefficacy are likely to have many self-regulatory learning strategies (e.g., self-monitoring, self-evaluation) that benefit their academic performance (Zimmerman et al., 2017) and wellbeing (Cattelino et al., 2020; Cobo-Rendón et al., 2020).

Self-efficacy beliefs not only exert a central role on positive thinking and hedonic balance, but they are considered a major resource in facilitating adolescents' coping (Burger \& Samuel, 2017). High levels of self-efficacy are associated with the definition and redefinition of personal goals, persistence and a constructive way of dealing with failures (Bandura, 1997). Furthermore, people with high self-efficacy have confidence in their own abilities and tend to face stressful demands and challenges with confidence. This attitude makes the adoption of positive and effective coping strategies more likely.

\section{Gender Differences}

Literature shows that, generally, during adolescence and youth, girls reported lesser levels of positive thinking and experienced less frequent and intense positive emotional states (Worrell et al., 2019). They also perceived higher selfregulative learning self-efficacy and self-efficacy in expressing their positive emotions, whereas boys perceived higher efficacy for dealing with negative affects (Bandura et al., 2003; Caprara \& Steca, 2005). Although efficacy beliefs and SWB differed as a function of gender, their relationship was essentially the same for both groups (Bandura et al., 2003; Caprara \& Steca, 2005). As far as coping is concerned, previous studies have not highlighted particularly significant relationships between gender and coping strategies (Litman, 2006).

\section{Aims and Hypotheses}

Based on Bandura's social-cognitive theory (Bandura, 1997), the present study examines the concurrent contribution of both affective and self-regulated learning self-efficacy beliefs on adolescents' and youths SWB (positivity and hedonic balance), and the contribution of both self-efficacy beliefs and SWB on positive coping strategies during the COVID-19 lockdown, controlling by gender and age. All adolescents and young people recruited were high school or university students.

Since the abilities to face difficulties and to resist are connected to everyday normative individual resources (Masten et al., 2021) and they have a pivotal role in the response to
COVID-19, in the present study it is assumed that home confinement and online learning, even if they represent difficult situations to face, may provide opportunities for those who possess higher emotional and self-regulated learning selfefficacy beliefs. Such individuals are able to handle important challenges and foster SWB, despite various difficulties; in turn, higher SWB, both cognitive and emotional, is expected to favour the use of positive coping strategies oriented towards positive acceptance, reinterpretation and use of active strategies.

Furthermore, direct relationships between emotional and academic self-efficacy and coping strategies are also hypothesised: those who have greater confidence in their own emotional regulation and in their self-regulated learning abilities are expected to be more able to use positive coping strategies, even without the mediation of positivity and hedonic balance. Based on current literature, the pattern of relationships is expected to be the same for boys and girls, and interactions between gender and self-efficacy beliefs and SWB are not expected.

Although the relationships between self-efficacy, wellbeing and coping strategies have already been investigated in literature, it is important to examine how these variables interact in adolescents and youths during a particularly stressful period such as the COVID-19 pandemic. Understanding how young people deal with and adapt to this negative experience could have important implications for the development of effective early intervention to promote positive functioning in specific adverse situations such prolonged lockdown.

\section{Method}

\section{Participants and Procedure}

Four hundred and eighty-five Italian students took part in the survey (girls $=74 \%$; mean age 19.3; range 14-24; standard deviation 2.4). Of the participants, $38 \%$ attended secondary high school and $62 \%$ attended university.

Data collection took place from May 13 to June 2, 2020. The study was conducted using an online survey through the Uniquest platform and was performed using the snowball sampling approach. Students of 18 years or older were contacted through via email with a brief description of the research project and a link to fill in the questionnaire. Students provided online informed consent and confirmed their voluntary participation to the study. In the case of students under 18 (the Italian legal age), an informative email was sent to parents, asking them to express consent for their children to participate in the research. All questionnaires were anonymous and were accompanied with an information regarding the research aims, data processing and instructions for compilation. The time required for the questionnaire was 
about $30 \mathrm{~min}$. Respondents took part on a voluntary basis and did not receive any compensation (or extra credit) for their participation. The research project was approved by the local Bioethics Committee of the University of Torino (N. 181,619/ 2020).

\section{Measures and Instruments}

The set of measures involved in this study are described below:

- Subjective well-being. Subjective well-being was measured through a cognitive and an emotional dimension. To assess the cognitive dimension, the positivity scale (Caprara et al., 2012) was used. Respondents were asked to express their agreement to 8 items about positive orientation towards life and future (e.g. "I look to the future with hope and enthusiasm") with responses ranging from 1 ("totally disagree") to 5 ("totally agree"). The range of the scale was $8-40$ (Cronbach's $\alpha$ was 0.85 and McDonald's $\omega_{\mathrm{T}}$ was 0.84 for the sample of this study). To assess the emotional dimension of well-being The International Positive and Negative Affect Schedule Short Form (I-PANAS-SF) (Terracciano et al., 2003; Thompson, 2007) was used. The PANAS scale measures the hedonic balance, given by the difference between positive and negative affect. It consists of a self-reported checklist designed to measure 5 positive (alert, inspired, determined, attentive, active) and 5 negative (upset, hostile, ashamed, nervous, scared) emotions. Participants were asked how often they experienced each emotion during lockdown, with answers ranging from 1 ("very slightly or not at all") to 5 ("extremely or very much"). The range of the two scales were 5-25 (Cronbach's $\alpha$ was 0.80 for Positive affect and 0.73 for Negative affect in the sample of this study and McDonald's $\omega_{\mathrm{T}}$, based on the estimates of a confirmatory bifactor model, was 0.95 ).

- Self-regulated learning self-efficacy. Adolescents' efficacy beliefs on self-regulated learning were assessed by the SESRL scale (Caprara, 2001). Participants were asked to answer to 10 items indicating their ability during lockdown, to plan and organize academic activities and their levels of self-motivation for academic work (e.g. "How much can you concentrate on your studies without being distracted?"). Participants answered on a 5-point scale ranging from 1 (totally unable) to 5 (extremely able). The range of the total scale was 10-50 (Cronbach's $\alpha$ was 0.88 and McDonald's $\omega_{\mathrm{T}}$ was 0.91 for the sample of this study).

- Regulatory emotional self-efficacy. Adolescents' efficacy beliefs in managing their positive and negative emotions were measured through 11 items selected from the Regulatory emotional self-efficacy (Caprara et al., 2008,
2013). Participants were asked to indicate how they dealt with different situations during lockdown. More specifically, 2 items referred to positive emotions (e.g. "how able are you to express your satisfaction when you reach the goals you set yourself"), 3 items referred to anger (e.g. "do you lose control of your actions when you're very angry"), 3 items referred to sadness (e.g. "are you able not to feel depressed in the face of difficulties") and 3 items referred to fear (e.g. "can you keep calm in situations where many others are afraid"). Participants rated the strength of their self-efficacy beliefs on a 5-point scale ranging from 1 (completely unable) to 5 (extremely able). The range of the total scale was $11-55$ (Cronbach's $\alpha$ was 0.80 for positive emotions and 0.84 for negative emotions for the sample of this study and McDonald's $\omega_{\mathrm{T}}$ based on the estimates of a confirmatory bifactor model, in which the group factor loadings of the two items of Positive emotion regulatory self-efficacy were constrained to be equal for identification purpose, were 0.80 and 0.77 for Positive and Negative emotions respectively).

- Coping strategies. Coping strategies were measured through 14 items selected from the COPE-NVI (Sica et al., 2008). Participants were asked to indicate how often they implemented each of the strategies listed, referring to their current experience. For this study the positive coping, composed by 5 items referred to problem-oriented coping ( 2 items; e.g. "I make every effort to be pro-active") and positive attitude ( 3 items; e.g. "I look for something positive in what is happening") were considered. Participants answered on a 4-point scale ranging from 1 (never or almost never) to 4 (always or almost always). The range of the scale was 5-20 (Cronbach's $\alpha$ was 0.66 and McDonald's $\omega_{\mathrm{T}}$ was 0.83 for the sample of this study).

\section{Procedures for Statistical Analysis}

Descriptive statistics of the study variables were performed using SPSS 26 and included t test and Cohen's d for gender differences and Pearson's correlations.

Structural equation modeling (SEM) with Mplus 8 (Muthén \& Muthén, 1998-2017) was used to examine the hypothesized pattern of relationships between self-efficacy, SWB and positive coping measures. The structural model was tested on the whole sample and across genders by using multiple group analysis. The multiple group analysis allowed us to test the hypothesized absence of a moderator role of the gender variable.

Adhering to current literature (Weston \& Gore Jr, 2006), prior to estimating the structural model the factorial structure of each scale was checked by applying confirmatory factor analysis (CFA). After confirming the factorial structures on 
the whole sample, multiple group CFAs were conducted to test for gender differences in model parameters.

Missing data, that ranged $0.0-5.4 \%$, were tested for randomness using Little's test (Little, 1998). The test was not statistically significant, indicating that missing could be considered completely at random. Consequently, a full information ML estimator was used both for CFAs and structural model estimation. Specifically, the MLR method was used with reference to both missing data and non-normality.

\section{Measurement Models}

For each of the five scales, a confirmatory factor analysis was performed to assess how well the data fitted the theoretical factor structure. Specifically, a two-factor model was estimated for the Panas scale (distinguishing between positive and negative affect) and for the regulatory emotional selfefficacy scale (distinguishing between positive and negative emotions and allowing the residual for sadness, anger and fear subscale to be correlated) and a one-factor model for the remaining scales (self-regulated learning self-efficacy, positivity and positive coping). Global model fit was evaluated according to the following criteria: root mean square error of approximation (RMSEA), comparative fit index (CFI) and standardized root mean squared residual (SRMR). Model fit to the data was considered acceptable in the case of CFI $\geq .90$, RMSEA $\leq$ .10 , and SRMR $\leq .10$ and excellent in case of CFI $\geq .95$, RMSEA $\leq .06$, and SRMR $\leq .08$ (Weston \& Gore Jr, 2006; Browne \& Cudeck, 1993; Hu \& Bentler, 1999).

After confirming the factorial structure of the separate scales, measurement invariance (configural, metric and scalar invariance) across genders was assessed. Firstly, the measurement invariance of Panas scale was evaluated, then the difference between the average of the positive emotion ratings and the average of the negative emotion ratings, named hedonic balance, was computed. Lastly, a measurement model including all the latent variables - self-regulated learning self-efficacy, regulatory positive and negative emotion self-efficacy, positivity and positive coping - was tested for measurement invariance between boys and girls. The observed variable hedonic balance was not included in the measurement model used to test for measurement invariance across genders to avoid having more free parameters than number of observations in the group of boys in which $N=124$. According to Chen (2007), a worsening greater or equal to .005 for $\Delta C F I$, supplemented by a worsening greater or equal to .010 or .025 for $\triangle$ RMSEA and $\triangle$ SRMR respectively when moving from configural to metric invariance was considered as a lack of metric invariance and a worsening greater or equal to .005 for $\triangle \mathrm{CFI}$, supplemented by a worsening greater or equal to .010 or .005 for $\triangle$ RMSEA and $\triangle$ SRMR respectively when moving from metric to scalar invariance was considered as a lack of scalar invariance.

\section{Structural Model}

In the structural model, self-regulated learning self-efficacy, regulatory positive and negative emotion self-efficacy, positivity and positive coping were introduced as latent variables and hedonic balance was introduced as an observed variable.

Self-regulated learning self-efficacy, regulatory positive and negative emotion self-efficacy latent variables, alongside gender $(1=$ boys $)$ and age $(1=$ university students $)$, were modelled as exogenous variables which influence both the two well-being measures (positivity and hedonic balance) and the outcome latent variable, that is positive coping. The two well-being measures in turn influence the outcome latent variable.

Global model fit was evaluated using the same criteria applied in CFAs. Local fit was assessed by examining standardized regression coefficients for significance and $R^{2}$ for each endogenous variable.

\section{Results}

\section{Descriptive Statistics}

A first descriptive analysis highlighted the absence of statistically significant gender differences with respect to selfregulated learning self-efficacy and positive emotion self-efficacy. Boys, compared to girls, reported greater confidence in their ability to manage negative emotions, greater positive coping and greater well-being in its dual value of positivity and hedonic balance (Table 1).

\section{Correlations between Study Variables}

All the variables considered in this study were statistically correlated and the results do not change when controlling for gender (Table 2).

\section{Measurement Models}

As shown in Table 3, the Self-regulated learning self-efficacy one-factor model did not fit adequately to the data (RMSEA $=.133$; CFI $=.829$; SRMR $=.063$ ), but met all the criteria $(\mathrm{RMSEA}=.076 ; \mathrm{CFI}=.948 ; \mathrm{SRMR}=.045)$ after the residual of two pairs of items were correlated (the two items dealing with maintaining the concentration when studying and the two dealing with planning didactic activities). The fit of the positive and negative emotion self-efficacy two-factor model was excellent $(\mathrm{RMSEA}=.045 ; \mathrm{CFI}=.977$; SRMR $=.041)$. As the residual correlations between items of the fear subscale were not statistically significant, they were set to zero without worsening the fit of the model $(\mathrm{RMSEA}=.047$; $\mathrm{CFI}=.973$; $\mathrm{SRMR}=.043)$. As regards the 
Table 1 Descriptive Statistics of the Study Variables in the Total Sample and by Gender

\begin{tabular}{|c|c|c|c|c|c|c|c|c|}
\hline & \multicolumn{2}{|c|}{$\begin{array}{l}\text { Total } \\
(\mathrm{N}=485)\end{array}$} & \multicolumn{2}{|c|}{$\begin{array}{l}\text { Girls } \\
(\mathrm{N}=361)\end{array}$} & \multicolumn{2}{|c|}{$\begin{array}{l}\text { Boys } \\
(\mathrm{N}=124)\end{array}$} & \multirow[t]{2}{*}{$\begin{array}{l}\mathrm{t} \text {-test } \\
\mathrm{p} \text { value }\end{array}$} & \multirow[t]{2}{*}{$\begin{array}{l}\text { Cohen's } \\
\text { d }\end{array}$} \\
\hline & M & $\mathrm{SD}$ & M & $\mathrm{SD}$ & M & $\mathrm{SD}$ & & \\
\hline Self-regulated learning selfefficacy & 34.2 & 6.9 & 34.2 & 6.8 & 34.0 & 7.0 & 0.788 & -0.03 \\
\hline Positive emotion self-efficacy & 7.0 & 1.8 & 7.0 & 1.8 & 7.0 & 1.8 & 0.798 & -0.03 \\
\hline Negative emotion self-efficacy & 24.9 & 6.0 & 23.9 & 5.6 & 28.0 & 6.0 & $<0.001$ & -0.72 \\
\hline Positivity & 27.1 & 6.2 & 26.3 & 6.1 & 29.5 & 5.8 & $<0.001$ & -0.54 \\
\hline Hedonic balance & 2.4 & 5.9 & 1.3 & 5.7 & 5.6 & 5.6 & $<0.001$ & -0.76 \\
\hline Positive coping & 13.3 & 2.8 & 13.0 & 2.7 & 14.0 & 2.9 & 0.001 & -0.35 \\
\hline
\end{tabular}

positivity one-factor model, fit measures were unsatisfactory (RMSEA = .174; CFI = .779; SRMR $=.079)$ and it was necessary to freely estimate the residual correlation of the three items dealing with hope and trust in the future to obtain an acceptable model fit to the data $(\mathrm{RMSEA}=.088$; $\mathrm{CFI}=.952$; SRMR =.041). Moving to the remaining scales, model fit was acceptable for the Panas scale (RMSEA $=.078$; CFI $=.908$; SRMR $=.051$ ) and excellent for the Positive coping scale $(\mathrm{RMSEA}=.043 ; \mathrm{CFI}=.982 ; \mathrm{SRMR}=.024)$.

Panas items showed metric invariance and partial scalar invariance for both boys and girls; in fact, the worsening of the fit indexes moving from configural to metric invariance model was negligible $(\triangle \mathrm{RMSEA}=-0.007 ; \Delta \mathrm{CFI}=0.004$; $\triangle$ RMSEA $=0.008)$, whereas both $\triangle \mathrm{CFI}$ and $\triangle \mathrm{RMSEA}$ did not fulfill the threshold values $(\triangle \mathrm{RMSEA}=0.002 ; \Delta \mathrm{CFI}=$ 0.014; $\triangle \mathrm{RMSEA}=0.005$ ) when moving from the metric to the scalar invariance model. The scalar invariance model was then re-specified relaxing the equality constrain on the intercept of one item, obtaining acceptable values for delta statistics $(\triangle \mathrm{RMSEA}=-0.001 ; \Delta \mathrm{CFI}=-0.005 ; \Delta \mathrm{SRMR}<0.001)$.

The measurement model including the five latent variables (self-regulated learning self-efficacy, regulatory positive and negative emotion self-efficacy, positivity and positive coping) showed both metric invariance $(\triangle \mathrm{RMSEA}=<0.001$; $\triangle \mathrm{CFI}=-0.001 ; \Delta \mathrm{SRMR}=0.003)$ and scalar invariance $(\triangle \mathrm{RMSEA}=0.002 ; \Delta \mathrm{CFI}=-0.014 ; \Delta \mathrm{SRMR}=0.002)$ (Table 4).

\section{Structural Model}

The hypothesized model (Fig. 1) fitted the data well $(\mathrm{RMSEA}=0.045 ; \mathrm{CFI}=0.911 ; \mathrm{SRMR}=0.057)$ and the explained variance was satisfactory for all the endogenous variables: Positivity (.44), hedonic balance (.57) and positive coping (.50). In relation to the standardized regression coefficients, the hypothesized relationships were mainly supported. Self-regulated learning self-efficacy was positively related to both the well-being latent variables (.19 for positivity and .31 for hedonic balance). In addition, self-efficacy in regulating positive emotion (Pos. Emotion Self-efficacy) was positively related to positivity (.43) and hedonic balance (.28). With regard to self-efficacy in regulating negative emotion (Neg. Emotion Self-efficacy), significant positive relations were found with positivity (.27), hedonic balance (.43) and positive coping (.36). When considering the relationship between wellbeing latent variables and positive coping, hedonic balance only was positively related to positive coping (.28). Contrary to our expectations, positivity and both self-regulated learning self-efficacy and self-efficacy in regulating positive emotion, were not related to positive coping.

In the case of control variables, gender was weakly related to positivity (.11) and hedonic balance (.16), with boys scoring higher than girls and age was also weakly related to hedonic balance (.13), with university students scoring higher than secondary school students.
Table 2 Relationship between Study Variables: Pearson's Correlation (Lower Triangular Part) and Partial Correlation Controlling for Gender (Upper Triangular Part)

\begin{tabular}{lllllll}
\hline & 1 & 2 & 3 & 4 & 5 & 6 \\
\hline 1. Self-regulated learning self-efficacy & - & 0.27 & 0.28 & 0.30 & 0.49 & 0.29 \\
2. Positive emotion self-efficacy & 0.27 & - & 0.20 & 0.47 & 0.42 & 0.28 \\
3. Negative emotion self-efficacy & 0.26 & 0.19 & - & 0.36 & 0.50 & 0.43 \\
4. Positivity & 0.30 & 0.43 & 0.40 & - & 0.57 & 0.39 \\
5. Hedonic balance & 0.47 & 0.39 & 0.54 & 0.60 & - & 0.46 \\
6. Positive coping & 0.30 & 0.26 & 0.45 & 0.41 & 0.49 & - \\
\hline
\end{tabular}

Note. All coefficients are statistically significant at $\mathrm{p}<0.001$. 
Table 3 Global fit measures of the measurement models

\begin{tabular}{llllll}
\hline Model & $\chi^{2}$ & df & RMSEA & CFI & SRMR \\
\hline Self-regulated learning self-efficacy $^{2}$ & 335.8 & 35 & 0.133 & 0.829 & 0.063 \\
Self-regulated learning self-efficacy $^{\mathrm{a}}$ & 125.5 & 33 & 0.076 & 0.948 & 0.045 \\
Positive and negative emotion self-efficacy $^{\mathrm{b}}$ & 67.8 & 34 & 0.045 & 0.977 & 0.041 \\
Positive and negative emotion self-efficacy $^{\mathrm{b}}$ & 75.8 & 37 & 0.047 & 0.973 & 0.043 \\
Positivity $^{\text {Positivity }}$ & 312.8 & 20 & 0.174 & 0.779 & 0.079 \\
Panas $^{\mathrm{c}}$ & 80.2 & 17 & 0.088 & 0.952 & 0.041 \\
Positive coping & 134.6 & 34 & 0.078 & 0.908 & 0.051 \\
\hline
\end{tabular}

Note. a) residual correlations for two pairs of items were freely estimated; b) residual correlations between items of the fear subscale set to zero; c) residual correlations between three pairs of items were freely estimated.
To test for interaction with the gender variable, two further models were specified. A baseline model in which regression coefficients were freely estimated in the two groups and a constrained model in which coefficients were constrained to be equal across groups. The fit of the baseline model $($ RMSEA $=0.054 ; \mathrm{CFI}=0.872 ; \mathrm{SRMR}=0.075)$ and that of the constrained model $(\mathrm{RMSEA}=0.054 ; \mathrm{CFI}=0.870$; SRMR $=0.077$ ) were acceptable; in both cases only CFI value was slightly lower than the cut-off value. Moreover, the worsening in model fit moving from the baseline to the constrained model was negligible $(\triangle \mathrm{RMSEA}<0.001 ; \Delta \mathrm{CFI}=-0.002$; $\triangle$ SRMR $=0.002$ ). Thus, the relationships shown in Fig. 1 held equally well in the boys and girls subsamples.

\section{Discussion and Conclusion}

In recent years, the importance of research on positive development in adolescents and youths (Lerner et al., 2018) and on optimal psychological functioning has gained growing attention (Seligman \& Csikszentmihalyi, 2000; Seligman, 2019). In this perspective, the present study analysed adolescents' and youths' subjective well-being (in terms of positivity and hedonic balance) during the COVID-19 pandemic and successive lockdown. It was a particularly challenging time, during which many daily activities were suddenly interrupted, with negative consequences on psychological well-being (WHO, 2020).

More specifically, this study analysed the concurrent contribution of affective (positive and negative) and self-regulated learning self-efficacy beliefs on the SWB of adolescents and youths and, in turn, the contribution of SWB on positive coping strategies, controlling by gender and age. A clear relationship between self-efficacy beliefs and positive coping strategies were also expected.

As assumed in our hypotheses, the findings suggested that all the forms of self-efficacy tested in the model are related to both cognitive and emotional well-being. It was in line with the Bandura's social-cognitive theory (Bandura, 1997) and with previous studies which stressed the significant role of self-efficacy in affecting cognitive, motivational and affective processes and in promoting positive thinking and hedonic balance or happiness (Bandura et al., 2003; Caprara et al., 2006). During the Italian lockdown, when adolescents and youths were facing new demands in school or university and new emotional challenges, self-efficacy beliefs in these areas
Table 4 Measurement Invariance across Boys and Girls for the Panas Scale and for the FiveLatent Variable Model

\begin{tabular}{lcccccccc}
\hline Model & $\chi^{2}$ & df & RMSEA & CFI & SRMR & $\Delta$ RMSEA & $\Delta$ CFI & $\Delta$ SRMR \\
\hline $\begin{array}{l}\text { Panas } \\
\quad \text { Configural }\end{array}$ & 162.3 & 64 & 0.080 & 0.908 & 0.056 & & & \\
$\quad \begin{array}{l}\text { invariance } \\
\text { Metric invariance }\end{array}$ & 166.0 & 72 & 0.073 & 0.912 & 0.064 & -0.007 & 0.004 & 0.008 \\
$\quad \begin{array}{l}\text { Scalar invariance } \\
\text { Scalar invariance }\end{array}$ & 188.3 & 80 & 0.075 & 0.898 & 0.069 & 0.002 & -0.014 & 0.005 \\
$\begin{array}{l}\text { Five-latent variable model } \\
\text { Configural }\end{array}$ & 178.1 & 79 & 0.072 & 0.907 & 0.064 & -0.001 & -0.005 & $<0.001$ \\
$\quad$ invariance & 1605.0 & 1013 & 0.049 & 0.896 & 0.070 & & & \\
$\quad \begin{array}{l}\text { Metric invariance } \\
\text { Scalar invariance }\end{array}$ & 1638.3 & 1040 & 0.049 & 0.895 & 0.073 & $<0.001$ & -0.001 & 0.003 \\
\hline
\end{tabular}

Note. a) Relaxing equality constrain on the intercept of one item. 
Fig. 1 Standardized coefficients for the model linking selfefficacy, well-being and coping latent variables, controlling for gender (Boys) and age (University students). Global fit measures: RMSEA $=0.045$, $\mathrm{CFI}=0.911, \mathrm{SRMR}=0.057 ; * * *$ $\mathrm{p}<0.001 ; * * \mathrm{p}<0.01 ; * \mathrm{p}<0.05$.

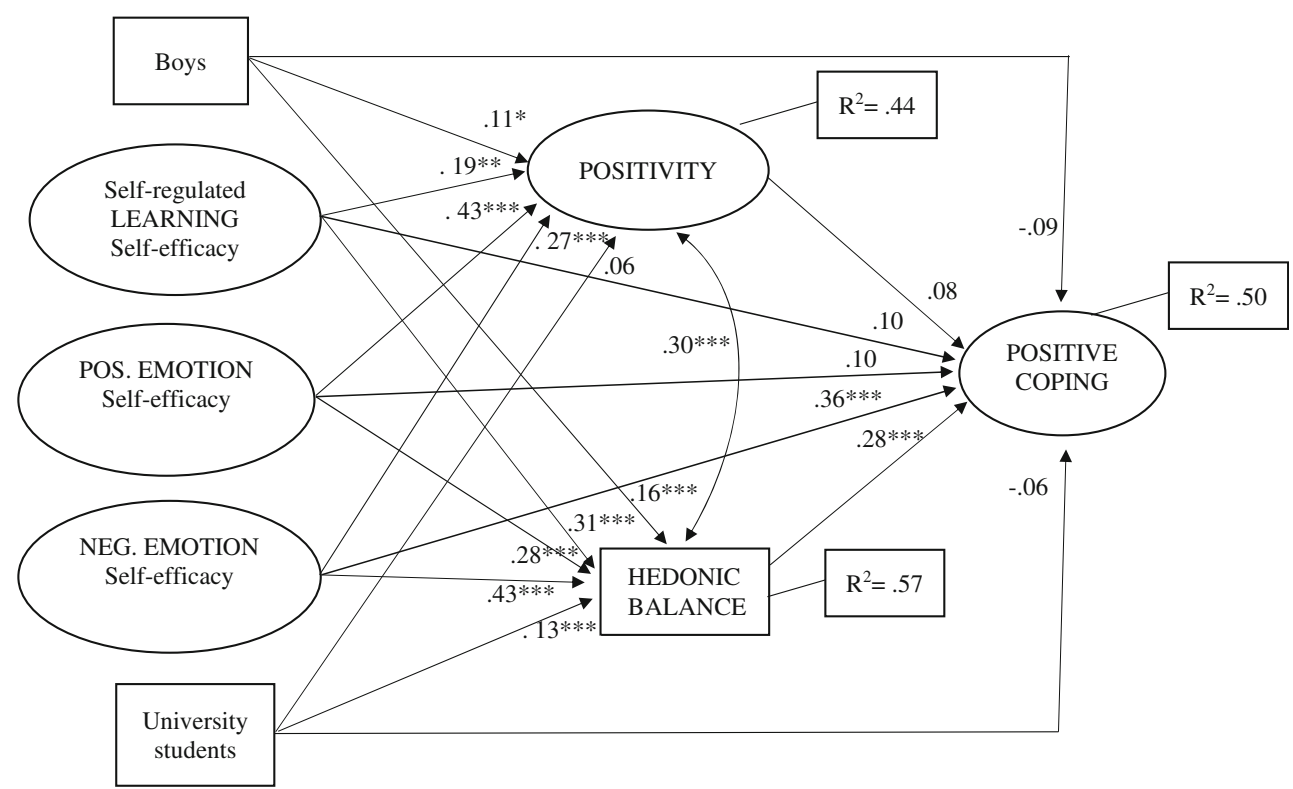

promoted subjective well-being, both in terms of hedonic balance and positivity (positive attitude toward self, life and future).

We found particularly strong connections between selfefficacy in regulating positive emotions and positivity, and between self-efficacy in regulating negative emotions and hedonic balance. This is an interesting finding that highlights how the ability to regulate positive emotions is an important variable in fostering personal satisfaction and positive orientation towards the future (positivity). On the other hand, the ability to regulate negative emotions is directly related to the emotional component of well-being, promoting happiness (hedonic balance).

The relationship between self-efficacy and coping strategies was only partially confirmed since a direct relation among the different forms of perceived self-efficacy on positive coping was not found, except for self-efficacy in regulating negative emotions. Previous studies (Carver \& Scheier, 2001) show the direct influence of self-efficacy beliefs on coping strategies, underlining that the latter depend substantially on the positive expectations that people have in achieving their goals or to solving particular problems. A higher perceived self-efficacy leads the individuals to try, even strenuously, to achieve their goals and to deal with their problems, using coping strategies aimed at the approach. On the contrary, negative expectations and a low perceived sense of control lead individuals to give up or to choose unsuccessful ways of managing psychological stress. In our sample the direct relation between self-efficacy beliefs and positive coping strategies was found only in the case of regulation of negative emotions. This finding is particularly relevant considering the specific period of confinement: the dramatic changes in everyday life, specifically in the spheres of school/university and relationships, and having to face with a pandemic of which little is known, required individuals to deal with negative emotions such as anger, sadness and fear. The successful regulation of these emotions is directly related to the use of positive coping strategies, even without the mediating role of positivity and hedonic balance.

The hypothesis of the influence of SWB on positive coping strategies was partially confirmed. These findings suggested that positive coping was related only to the emotional component of well-being, while any significant relation with cognitive dimension was found. Therefore, the three forms of selfefficacy beliefs favoured hedonic balance and positivity, but the latter did not promote the implementation of positive coping strategies, as in the case of hedonic balance. In other words, the cognitive component, as measured by positivity, is not linked to a greater or lesser use of positive coping when the emotional component is included in the model.

These findings lead to interesting reflection. During the lockdown, the emotional component of well-being was related to the implementation of positive coping, oriented to positive attitude and the specific approach to problems. Positive orientation towards life and the future was less important than the subjective perception of feeling good emotionally. Reflection regarding the two dimensions of SWB is pivotal. Although a positive and significant correlation between positivity and hedonic balance was found, suggesting that they are specific aspects of the same construct, the pathways of relations suggested that SWB is a multi-faceted construct, in line with previous studies (Diener et al., 2002). As stressed by Davern et al. (2007), the affective-cognitive model of SWB is theoretically only demonstrable in circumstances favourable to the normal homeostatic maintenance of SWB. If sufficiently aversive conditions are encountered, such as those which generate 
strong discrepancies between desired and experienced conditions, homeostasis will fail. Under such conditions (as can be represented by the prolonged confinement situation), the experience of SWB is anticipated to shift from pleasant to unpleasant emotions generated by the challenging agent. Therefore, it is possible to affirm that, in particularly stressful conditions, the emotional dimension can play a predominant role over its cognitive counterpart in adolescents and youths.

This investigation has some limitations. The first involves the cross-sectional nature of the study, thus it is not possible to infer causal relationships. Future longitudinal studies should be conducted to confirm the presence of a causal trend among affective and self-regulated learning self-efficacy, SWB and positive coping. Secondly, the sample was not randomly selected and there were more girls than boys; it was not possible to increase the number of boys involved in the study because data collection took place during the lockdown period and was interrupted when the most stringent limitations were lifted in Italy (June 3, 2020).

Despite these limitations, the pathways of relationships tested in the model were based on solid theories that have been proven in previous longitudinal investigations (Caprara et al., 2006). Moreover, this study has the added value of having been conducted in a unique period of confinement and of having involved a sample of students facing the challenges due by the COVID-19 pandemic added to the many developmental tasks that adolescents and youths face in everyday life.

Our findings underline the importance of well-being (especially in its emotional dimension) when facing the myriad challenges and difficulties during the period of pandemic and lockdown, adopting positive attitudes and problemoriented coping. These strategies are considered by most scholars to be more adaptive than avoidance coping, which, in the long term, does not allow for the collection of useful information relating to the problem, compromising the use of useful resources (Litman, 2006). SWB during the period of confinement was related to self-regulating mechanisms, in particular to self-efficacy beliefs: it emphasised the importance, especially for adolescent and youth students, of feeling able to face challenges in the fields of learning and emotional regulation. These findings have important implications, since self-regulation processes, in particular self-efficacy beliefs, can be promoted and gradually improved. Bandura's social cognitive theory (Bandura, 1997) highlighted the active mastery experience, vicarious experience, verbal/social persuasion, physiological and affective states as sources of self-efficacy. Parents and teachers can act on these sources by helping adolescents and youths to have successful experiences both in emotional self-regulation and in the self-regulated learning by offering opportunities to get involved and by helping them to become aware of their successes, also through the narration so important in adolescence for the self-definition. Moreover, verbal sharing, with adults and peers, of the emotions experienced and the strategies to regulate them can promote vicarious learning. Additionally, adults can support adolescents' self-regulation through verbal support and by expressing confidence in their abilities. By doing so, they foster a climate of warmth, affection and trust that promotes the SWB in its double affective and cognitive component. The results of this study highlight, during the lockdown, the centrality of self-efficacy in the management of negative emotions; in this regard, it may also be useful to integrate body relaxation exercises, breathing regulation, music and singing with cognitive strategies related to reflection and narration.

Paying special attention to self-efficacy in emotional management and specifically to basic negative emotions (anger, sadness and fear) can affect SWB and promote positive coping strategies to face challenges and difficulties that arise from everyday life and especially from non-normative events.

Data Availability The data that support the findings of this study are not publicly available as they contain information that could compromise research participant privacy and consent.

\section{Declarations}

Ethical Approval All procedures involving human participants in this study were performed in accordance with the principles of the Declaration of Helsinki. Approval was obtained from the ethics committee of the University of Torino (N. 181,619/2020).

Informed Consent Informed consent was obtained from all individual participants included in the study.

Conflict of Interest The Authors declare that they have no conflicts of interest.

\section{References}

Arnett, J. J. (2011). Emerging adulthood(s): The cultural psychology of a new life stage. In L. A. Jensen (Ed.), Bridging cultural and developmental approaches to psychology: New syntheses in theory, research, and policy (p. 255-275). Oxford University Press.

Bandura, A. (1997). Self-efficacy: The exercise of control. W H Freeman/ Times Books/ Henry Holt \& Co..

Bandura, A., Caprara, G. V., Barbaranelli, C., Gerbino, M., \& Pastorelli, C. (2003). Role of affective self-regulatory efficacy in diverse spheres of psychosocial functioning. Child Development, 74(3), 769-782. https://doi.org/10.1111/1467-8624.00567.

Bonino S., \& Cattelino E. (2012) "Italy". In J. J. Arnett (Ed.), Adolescent psychology around the world (pp. 290-305). Psychology Press.

Browne, M. W., \& Cudeck, R. (1993). Alternative ways of assessing model fit. In K. A. Bollen \& J. S. Long (Eds.), Testing Structural Equation Models (pp. 136-162). Sage.

Burger, K., \& Samuel, R. (2017). The role of perceived stress and selfefficacy in young people's life satisfaction: A longitudinal study. Journal of Youth and Adolescence, 46, 78-90. https://doi.org/10. 1007/s10964-016-0608-x.

Busseri, M. A., \& Sadava, S. W. (2013). Subjective well-being as a dynamic and agentic system: Evidence from a longitudinal study. 
Journal of Happiness Studies, 14(4), 1085-1112. https://oi.org/10. 1007/s10902-012-9368-9.

Calandri, E., Graziano, F., Cattelino, E., \& Testa, S. (2021). Depressive symptoms and loneliness in early adolescence: The role of empathy and emotional self-efficacy. Journal of Early Adolescence, 41(3), 369-393. https://doi.org/10.1177/0272431620919156.

Caprara, G. V. (Ed.) (2001). La valutazione dell'autoefficacia. Costrutti e strumenti [The evaluation of self-efficacy. Constructs and instruments]. Erickson.

Caprara, G. V., Alessandri, G., Eisenberg, N., Kupfer, A., Steca, P., Caprara, M. G., Yamaguchi, S., Fukuzawa, A., \& Abela, J. (2012). The positivity scale. Psychological Assessment, 24(3), 701-712. https://doi.org/10.1037/a0026681.

Caprara, G. V., Di Giunta, L., Eisenberg, N., Gerbino, M., Pastorelli, C., \& Tramontano, C. (2008). Assessing regulatory emotional selfefficacy in three countries. Psychological Assessment, 20(3), 227 237. https://doi.org/10.1037/1040-3590.20.3.227.

Caprara, G. V., Di Giunta, L., Pastorelli, C., \& Eisenberg, N. (2013). Mastery of negative affect: A hierarchical model of emotional selfefficacy beliefs. Psychological Assessment, 25(1), 105-116. https:// doi.org/10.1037/a0029136.

Caprara, G. V., Eisenberg, N., \& Alessandri, G. (2017). Positivity: The dispositional basis of happiness. Journal of Happiness Studies, 18, 353-371. https://doi.org/10.1007/s10902-016-9728-y.

Caprara, G. V., \& Steca, P. (2005). Affective and social self-regulatory efficacy beliefs as determinants of positive thinking and happiness. European Psychologist, 10(4), 275-286. https://doi.org/10.1027/ 1016-9040.10.4.275.

Caprara, G. V., Steca, P., Gerbino, M., Paciello, M., \& Vecchio, G. M. (2006). Looking for adolescents' well-being: Self-efficacy beliefs as determinants of positive thinking and happiness. Epidemiologia e Psichiatria Sociale, 15(1), 30-43. https://doi.org/10.1017/ S1121189X00002013.

Carver, C. S., \& Scheier, M. F. (2001). On the self-regulation of behavior. Cambridge University Press.

Cattelino, E., Chirumbolo, A., Baiocco, R., Calandri, E., \& Morelli, M. (2020). School achievement and depressive symptoms in adolescence: The role of self-efficacy and peer relationships at school. Child Psychiatry \& Human Development, 1-8. https://doi.org/10. 1007/s10578-020-01043-Z.

Cattelino, E., Morelli, M., Baiocco, R., \& Chirumbolo, A. (2019). From external regulation to school achievement: The mediation of selfefficacy at school. Journal of Applied Developmental Psychology, 60, 127-133. https://doi.org/10.1016/j.appdev.2018.09.007.

Chen, F. F. (2007). Sensitivity of goodness of fit indexes to lack of measurement invariance. Structural Equation Modeling: A Multidisciplinary Journal, 14(3), 464-504. https://doi.org/10.1080/ 10705510701301834.

Cobo-Rendón, R., Pérez-Villalobos, M. V., Páez-Rovira, D., \& GraciaLeiva, M. (2020). A longitudinal study: Affective wellbeing, psychological wellbeing, self-efficacy and academic performance among first-year undergraduate students. Scandinavian Journal of Psychology, 61(4), 518-526. https://doi.org/10.1111/sjop.12618.

D'Amico, S., Marano, A., Geraci, M. A., \& Legge, E. (2013). Perceived self-efficacy and coping styles related to stressful critical life events. PLoS One, 8(7), 1-7. https://doi.org/10.1371/journal.pone. 0067571

Dahl, R. E. (2001). Affect regulation, brain development, and behavioral/ emotional health in adolescence. CNS Spectrums, 6(1), 60-72. https://doi.org/10.1017/s1092852900022884

Davern, M. T., Cummins, R. A., \& Stokes, M. A. (2007). Subjective wellbeing as an affective-cognitive construct. Journal of Happiness Studies, 8(4), 429-449. https://doi.org/10.1007/s10902007-9066-1.
Deci, E. L., \& Ryan, R. M. (2008). Hedonia, eudaimonia, and well-being: An introduction. Journal of Happiness Studies, 9(1), 1-11. https:// doi.org/10.1007/s10902-006-9018-1.

Diener, E. (2008). "Myths in the science of happiness, and directions for future research". In M. Eid \& R. J. Larsen (Eds.), The science of subjective well-being (pp. 493-514). Guilford.

Diener, E., Lucas, R. E., \& Oishi, S. (2002). Subjective well-being: The science of happiness and life satisfaction. In C. R. Snyder \& S. J. Lopez (Eds.), The handbook of positive psychology (pp. 63-73). Oxford University Press.

Duan, L., Shao, X., Wang, Y., Huang, Y., Miao, J., Yang, X., \& Zhu, G. (2020). An investigation of mental health status of children and adolescents in China during the outbreak of COVID-19. Journal of Affective Disorders, 275(1), 112-118. https://doi.org/10.1016/j. jad.2020.06.029.

Folkman, S., \& Lazarus, R. S. (1985). If it changes it must be a process: Study of emotion and coping during three stages of a college examination. Journal of Personality \& Social Psychology, 48(1), 150170. https://doi.org/10.1037/0022-3514.48.1.150.

Fredrickson, B. L., \& Joiner, T. (2018). Reflections on positive emotions and upward spirals. Perspectives on Psychological Science, 13(2), 194-199. https://doi.org/10.1177/1745691617692106.

Freire, C., Ferradás, M. M., Valle, A., Núñez, J. C., \& Vallejo, G. (2016). Profiles of psychological well-being and coping strategies among university students. Frontiers in Psychology, 7, 1554. https://doi. org/10.3389/fpsyg.2016.01554.

Hu, L. T., \& Bentler, P. M. (1999). Cutoff criteria for fit indexes in covariance structure analysis: Conventional criteria versus new alternatives. Structural Equation Modeling: A Multidisciplinary Journal, 6(1), 1-55. https://doi.org/10.1080/10705519909540118.

Jackson, S., \& Goossens, L. (Eds.). (2006). Handbook of adolescent development. Psychology Press.

Jiang, X., Fang, L., \& Lyons, M. D. (2019). Is life satisfaction an antecedent to coping behaviors for adolescents? Journal of Youth and Adolescence, 48(11), 2292-2306. https://doi.org/10.1007/s10964019-01136-6.

Lerner, R. M., Lerner, J. V., Geldhof, G. J., Gestsdóttir, S., King, P. E., Sim, A. T. R., Batanova, M., Tirrell, J. M., \& Dowling, E. (2018). Studying positive youth development in diferent nations: Theoretical and methodological issues. In J. J. Lansford \& P. Banati (Eds.), Handbook on adolescent development research and its impact on global policy (pp. 68-83). Oxford University Press.

Lerner, R. M., \& Steinberg, L. (Eds.). (2009). Handbook of adolescent psychology, volume 1: Individual bases of adolescent development (Vol. 1). John Wiley \& Sons.

Litman, J. A. (2006). The COPE inventory: Dimensionality and relationships with approach- and avoidance-motives and positive and negative traits. Personality and Individual Differences, 41(2), 273-284. https://doi.org/10.1016/j.paid.2005.11.032.

Little, R. J. A. (1998). A test of missing completely at random for multivariate data with missing values. Journal of the American Statistical Association, 83(404), 1198-1202. https://doi.org/10. 1080/01621459.1988.10478722.

Loades, M. E., Chatburn, E., Higson-Sweeney, N., Reynolds, S., Shafran, R., Brigden, A., Linney, C., McManus, M. N., Borwick, C., \& Crawley, E. (2020). Rapid systematic review: The impact of social isolation and loneliness on the mental health of children and adolescents in the context of COVID-19. Journal of the American Academy of Child \& Adolescent Psychiatry, 59(11), 12181239.e3. https://doi.org/10.1016/j.jaac.2020.05.009.

Masten, A. S., Lucke, C. M., Nelson, K. M., \& Stallworthy, I. C. (2021). Resilience in development and psychopathology: Multisystem perspectives. Annual Review of Clinical Psychology, 17, 521-549. https://doi.org/10.1146/annurev-clinpsy-081219-120307.

Mayordomo-Rodríguez, T., Meléndez-Moral, J. C., Viguer-Segui, P., \& Sales-Galán, A. (2015). Coping strategies as predictors of well- 
being in youth adult. Social Indicators Research, 122(2), 479-489. https://doi.org/10.1007/s11205-014-0689-4.

Morelli, M., Cattelino, E., Baiocco, R., Longobardi, E., Trumello, C., Babore, A., Candelori, C., \& Chirumbolo, A. (2021). Parents' psychological factors promoting children's mental health and emotional regulation during the COVID-19 lockdown. Maltrattamento e Abuso all'Infanzia, 23(1), 47-63. https://doi.org/10.3280/ MAL2021-001004.

Morelli, M., Cattelino, E., Baiocco, R., Trumello, C., Babore, A., Candelori, C., \& Chirumbolo, A. (2020). Parents and children during the COVID-19 lockdown: The influence of parenting distress, parenting self-efficacy, and children emotional well-being. Frontiers in Psychology, 11, 584645. https://doi.org/10.3389/ fpsyg.2020.584645.

Muthén, L.K. \& Muthén, B.O. (1998-2017). Mplus User's Guide. Eighth Edition. Muthén \& Muthén.

Pierce, M., Hope, H., Ford, T., Hatch, S., Hotopf, M., John, A., Kontopantelis, E., Webb, R., Wessely, S., McManus, S., \& Abel, K. M. (2020). Mental health before and during the COVID-19 pandemic: a longitudinal probability sample survey of the UK population. Lancet Psychiatry, 7(10), 883-892. https://doi.org/10.1016/ S2215-0366(20)30308-4.

Pigaiani, Y., Zoccante, L., Zocca, A., Arzenton, A., Menegolli, M., Fadel, S., Ruggeri, M., \& Colizzi, M. (2020). Adolescent lifestyle behaviors, coping strategies and subjective wellbeing during the COVID19 pandemic: An online student survey. Healthcare, 8(4), 472. Multidisciplinary Digital Publishing Institute. https://doi.org/10. 3390/healthcare8040472.

Saurabh, K., \& Ranjan, S. (2020). Compliance and psychological impact of quarantine in children and adolescents due to Covid-19 pandemic. The Indian Journal of Pediatrics, 87(7), 532-536. https://doi.org/ 10.1007/s12098-020-03347-3.

Seligman, M. E. P., \& Csikszentmihalyi, M. (2000). Positive psychology: An introduction. American Psychologist, 55(1), 5-14. https://doi. org/10.1037//0003-066X.55.1.5.

Seligman, M. E. P. (2019). Positive psychology: A personal history. Annual Review of Clinical Psychology, 15(1), 1-23. https://doi. org/10.1146/annurev-clinpsy-050718-095653.

Shiota, M. N. (2006). Silver linings and candles in the dark: Differences among positive coping strategies in predicting subjective well-being. Emotion, 6(2), 335-339. https://doi.org/10.1037/1528-3542.6. 2.335 .

Sica, C., Magni, C., Ghisi, M., Altoé, G., Sighinolfi, C., Chiri, L. R., \& Franceschini, S. (2008). Coping Orientation to Problems Experienced-Nuova Versione Italiana (COPE-NVI): uno strumento per la misura degli stili di coping. Psicoterapia Cognitiva e Comportamentale/Italian Journal of Cognitive and Behavioural
Psychotherapy, 14(1), 27-53. Available from: https://www. researchgate.net/publication/285817368 Coping Orientation to the Problems_Experiences-new Italian_version_COPE-NVI.

Terracciano, A., McCrae, R. R., \& Costa Jr., P. T. (2003). Factorial and construct validity of the Italian positive and negative affect schedule (PANAS). European Journal of Psychological Assessment, 19(2), 131-141. https://doi.org/10.1027//1015-5759.19.2.131.

Thompson, E. R. (2007). Development and validation of an internationally reliable short-form of the positive and negative affect schedule (PANAS). Journal of Cross-Cultural Psychology, 38(2), 227-242. https://doi.org/10.1177/0022022106297301.

Worrell, F. C., Andretta, J. R., Wells, K. E., Cole, J. C., \& McKay, M. T. (2019). Time attitudes and mental well-being, psychological, and somatic symptomatology in final year high school students. Current Psychology, 1-12. https://doi.org/10.1007/s12144-01900386-8.

Weston, R., \& Gore Jr., P. A. (2006). A brief guide to structural equation modeling. The Counseling Psychologist, 34(5), 719-751. https:// doi.org/10.1177/0011000006286345.

WHO (2020). Mental health and psychosocial considerations during the COVID-19 outbreak. Retrieved from https://www.who.int/docs/ default-source/coronaviruse/mental-health-considerations.pdf? sfvrsn $=6 \mathrm{~d} 3578$ af 2

Yap, S. T., \& Baharudin, R. (2016). The relationship between adolescents' perceived parental involvement, self-efficacy beliefs, and subjective well-being: A multiple mediator model. Social Indicators Research, 126(1), 257-278. https://doi.org/10.1007/s11205-0150882-0.

Zajacova, A., Lynch, S. M., \& Espenshade, T. J. (2005). Self-efficacy, stress, and academic success in college. Research in Higher Education, 46, 677-706. https://doi.org/10.1007/s11162-0044139-z.

Zambianchi, M., \& Bitti, P. E. R. (2014). The role of proactive coping strategies, time perspective, perceived efficacy on affect regulation, divergent thinking and family communication in promoting social well-being in emerging adulthood. Social Indicators Research, 116(2), 493-507. https://doi.org/10.1007/s11205-013-0307-x.

Zimmerman, B. J., Schunk, D. H., \& Boucher, K. L. (2017). "The role of self-efficacy and related beliefs in self-regulation of learning and performance". In A. J. Elliot, C. S. Dweck, \& D. S. Yeager (Eds.), Handbook of competence and motivation: theory and application (pp. 313-334). Guilford.

Publisher's Note Springer Nature remains neutral with regard to jurisdictional claims in published maps and institutional affiliations. 